\title{
Characterization of a novel Cry8Ea3-binding V-ATPase Subunit A in Holotrichia parallela
}

\author{
W. Wei ${ }^{1}$, G. Wei ${ }^{2}$, Z. Dan ${ }^{1}$, Y. Xiaoping ${ }^{1}$ and Z. Yakun ${ }^{1}$ \\ ${ }^{1}$ College of Plant Protection, Agricultural University of Hebei, \\ Baoding, Hebei, China \\ ${ }^{2}$ College of Plant Science and Technology, \\ Beijing University of Agriculture, Beijing, China \\ Corresponding author: G. Wei \\ E-mail: 1787421502@qq.com
}

Genet. Mol. Res. 15 (3): gmr.15038994

Received July 21, 2016

Accepted August 1, 2016

Published September 2, 2016

DOI http://dx.doi.org/10.4238/gmr.15038994

Copyright (C) 2016 The Authors. This is an open-access article distributed under the terms of the Creative Commons Attribution ShareAlike (CC BY-SA) 4.0 License

\begin{abstract}
Several receptor proteins of Cry toxin have been previously identified, including cadherin-like, aminopeptidase $\mathrm{N}$, and alkaline phosphatase. In the present work, a novel binding protein, V-ATPase subunit A (HpVAA), was identified in Holotricia parallela larvae and characterized. We performed reverse transcriptionpolymerase chain reaction and rapid amplification of cDNA ends technology to obtain the cDNA of the full-length hpvaa. Sequencing analysis showed that the open reading frame of hpvaa (GenBank accession No. KU497557) is 1845 bp long, encoding 614 amino acid residues. The predicted molecular weight and isoelectric point of HpVAA were $67.85 \mathrm{kDa}$ and 4.9, respectively. The HpVAA protein, which includes two putative conserved domains, ATP-synt_ab_N and ATP-synt_ab_C, and a Walker A (GAFGCGKT) motif and a Walker $\mathrm{B}$ (SMMADD) motif, possesses the same structural characteristics as V-ATPase subunit A from other insects. The protein was successfully
\end{abstract}

Genetics and Molecular Research 15 (3): gmr.15038994 
expressed in Escherichia coli, and a ligand blot assay showed binding of the protein with Cry8Ea3 toxin. Transcriptional analysis of hpvaa in different tissues of $H$. parallela larvae was performed by qRT-PCR, which showed that the relative expression of hpvaa in the Malpighian tubules is higher than that in other tissues.

Key words: Holotricia parallela; V-ATPase subunit A; Ligand blot; qRT-PCR

\section{INTRODUCTION}

Holotricia parallela belongs to the order Coleoptera, family Scarabeidae, and its larvae are commonly recognized as the most significant domestic underground pest affecting peanut, sweet potato, and potato which caused substantial reductions in crop yields (Yu et al., 2006; Shu et al., 2009b). Recent studies have shown that Bacillus thuringiensis (Bt) toxin Cry8-type had specific activity against coleopteran larvae (Sato et al., 1994; Yamaguchi et al., 2008). Cry8like, Cry8Ab, Cry8Ea, Cry8Ga, and Cry8Na1 were proven to widely used for control of $H$. parallela (Shu et al., 2009a,b; Zhang et al., 2013; Li et al., 2014). This finding provided the basis for the development of biological agents and the cultivation of transgenic crops.

Furthermore, the mechanism of the insecticidal effect of Bt has been demonstrated to be related to brush border membrane vesicles receptor protein in insect midgut epithelial cells (Bravo et al., 1992; Soberón et al., 2009). There were two potential modes to explain the underlying mechanism of toxicity of Cry proteins. Previous studies have proposed that the process of toxin oligomerization and membrane-pore formation were extremely enhanced by toxin-receptor interaction which subsequently led to midgut cell lysis and eventually death (Pardo-López et al., 2006a, 2013). In the signal transduction model (Zhang et al., 2006), the binding of Cry toxin to cadherin receptors causes an intracellular signal transduction that activates $\mathrm{G}$ protein and adenosine cyclase, leading to elevated cyclic adenosine monophosphate and activation of protease A, eventually leading to cell death. Several putative receptors have been described for Cry toxins, including cadherin-like (Vadlamudi et al., 1993; Hua et al., 2014; Zúñiga-Navarrete et al., 2015), aminopeptidase N (Knight et al., 1995; Gómez et al., 2012; Aroonkesorn et al., 2015), and alkaline phosphatase (Upadhyay and Singh, 2011; Zúñiga-Navarrete et al., 2013). In addition, some other proteins have been shown to bind with Cry protein, including V-ATPase A subunit (Krishnamoorthy et al., 2007) and B subunit (Bayyareddy et al., 2009), actin (McNall and Adang, 2003), and ABC transporter (Tanaka et al., 2013), as well glucose and lipids (Griffitts et al., 2005).

In this study, the cDNA of the full-length $H$. parallela V-ATPase subunit A (hpvaa) gene was cloned from larvae midguts for the first time, and the HpVAA protein was separated from Escherichia coli. To test the binding ability of the protein with the coleopteran-specific toxin Cry8Ea3, ligand blot experiments were carried out. Furthermore, we used quantitative reverse transcription-polymerase chain reaction (qRT-PCR) to determine the transcriptional level of the hpvaa gene in different larval tissues of $H$. parallela.

\section{MATERIAL AND METHODS}

\section{Insects}

H. parallela were collected from a field in Baoding, China, and the adults were

Genetics and Molecular Research 15 (3): gmr.15038994 
generally reared in the rearing chamber with fresh elm tree (Ulmus pumila) leaves. The larvae were reared with artificial feed from this Lab.

\section{Preparation of Cry toxin}

BTGWL, Cry8Ea3 (GenBank: KC855216.1) engineering strains were cultured in 1/2 Luria-Bertani medium supplemented with ampicillin and erythromycin at $30^{\circ} \pm 1^{\circ} \mathrm{C}$ until complete autolysis, and spore crystal mixtures were prepared. The Cry8Ea3 crystal proteins were prepared by differential centrifugation. Cry8Ea3 protoxin was activated by trypsin and subsequently separated by SDS-PAGE.

\section{Cloning of the hpvaa gene}

Total RNA was extracted $15 \mathrm{mg}$ of fresh midguts of third-instar $H$. parallela larvae using the RNAprep pure Tissue Kit (Tiangen, Beijing, China) from. Then the total RNA was basically used to prepare the first-strand cDNA using the GoScript ${ }^{\mathrm{TM}}$ Reverse Transcription System (Promega, Madison, WI, USA). Simultaneously, a pair of hpvaa-degenerate primers was designed based on V-ATPase subunit A sequences of Tribolium castaneum (GenBank: XM_971095), Bombyx mori (GenBank: NM_001098359), and Ostrinia furnacalis (GenBank: HQ434762). Next, we employed 5' and 3' rapid amplification of cDNA ends (RACE) with specific primers to get the fulllength sequence using SMARTER RACE cDNA Amplification Kit (Clontech, Mountain View, CA, USA). Each PCR (15 $\mu \mathrm{L}$ total volume) contained $11.47 \mu \mathrm{L} \mathrm{ddH}_{2} \mathrm{O}, 1.5 \mu \mathrm{L}$ 10X LA Buffer, $0.3 \mu \mathrm{L}$ dNTP, $0.3 \mu \mathrm{L}$ each specific primer, $1 \mu \mathrm{L}$ first-strand cDNA template, and $0.13 \mu \mathrm{L}$ LA Taq polymerase (Promega). The PCR program was as follows: one cycle of $94^{\circ} \mathrm{C}$ for $4 \mathrm{~min} ; 30$ cycles of $94^{\circ} \mathrm{C}$ for $45 \mathrm{~s}, 63^{\circ} \mathrm{C}$ for $45 \mathrm{~s}$, and $72^{\circ} \mathrm{C}$ for $1 \mathrm{~min}$ and $40 \mathrm{~s}$; and a final cycle at $72^{\circ} \mathrm{C}$ for $10 \mathrm{~min}$.

\section{Expression of HpVAA protein in $E$. coli BL21}

The open reading frame of hpvaa was amplified, purified with Universal DNA Purification Kit (Tiangen), and cloned into pET30a vector via restriction enzymes digestion (SalI and NotI).

The strain BL21 (pET30a-hpvaa) was cultured in Luria-Bertani medium at $37^{\circ} \mathrm{C}$, and induced by isopropyl- $\beta$-D-1-thiogalactopyranoside for 4 and $8 \mathrm{~h}$; BL21(pET30a) served as the negative control. HpVAA protein was loaded onto $10 \%$ SDS-PAGE and then transferred to polyvinylidene fluoride membranes to determine its expression. In brief, the membrane with the transferred proteins was blocked for $1 \mathrm{~h}$ with $1 \%$ bovine serum albumin at room temperature. After blocking the membrane was incubated with anti-His (1:5000 in Tris-buffered saline [TBS]) mouse antibodies (Boster, Wuhan, China) for $1 \mathrm{~h}$, followed by washing with TBS four times for $5 \mathrm{~min}$, and then with Tween (TBS-T) washing once for $5 \mathrm{~min}$. The membrane was subsequently incubated with second antibodies (goat anti-mouse antibodies, 1:10000 in TBS) for $1 \mathrm{~h}$, and the same washing steps were applied as described above. Detection was performed with Nitrotetrazolium Blue chloride (NBT) and 5-Bromo-4-Chloro-3-Indolyl Phosphate (BCIP).

\section{Ligand blot analysis of HpVAA protein}

After separating with $10 \%$ SDS-PAGE, HpVAA protein was transferred onto a 
polyvinylidene fluoride membrane, and incubated in blocking buffer, $1 \%$ bovine serum albumin in TBS, for $1 \mathrm{~h}$. The blocked membrane was then incubated with $20 \mathrm{mg} / \mathrm{mL}$ Cry $8 \mathrm{Ea} 3$ toxin proteins, activated by trypsin in blocking buffer, and washed with TBS and TBS-T. The blocked membrane was incubated with Cry8Ea3 primary antibodies (rabbit polyclonal antibody, 1:5000 in TBS) for $1 \mathrm{~h}$ and then conjuncted with anti-rabbit secondary antibody for $1 \mathrm{~h}$. The immunoblots were developed with NBT and BCIP.

\section{qRT-PCR}

Total RNA was traditionally separated from the midgut, foregut, hindgut, Malpighian tubules, fat body, peritrophic membrane, and egg of $H$. parallela. cDNA was synthesized and primers were designed as described above. The cDNA was amplified by qRT-PCR with specific primers (Light Cycler $^{\circledR} 96$ PCR Detection system, Roche, Germany). Each PCR (20 $\mu \mathrm{L}$ total volume) contained $10 \mu \mathrm{L}$ SYBR Premix EX Taq II, $1 \mu \mathrm{L}$ each specific primer, $1 \mu \mathrm{L}$ cDNA template, and $7 \mu \mathrm{L} \mathrm{ddH_{2 }} \mathrm{O}$. PCR amplification conditions were as follows: $95^{\circ} \mathrm{C}$ for $300 \mathrm{~s}, 45$ cycles of $95^{\circ} \mathrm{C}$ for $10 \mathrm{~s}, 56^{\circ} \mathrm{C}$ for $20 \mathrm{~s}$, and $72^{\circ} \mathrm{C}$ for $20 \mathrm{~s}$. The relative quantities of hpvaa transcripts were assessed using the $2^{-\Delta \Delta \mathrm{Ct}}$ method and normalized with $\beta$-actin.

\section{RESULTS}

\section{Cloning and analysis of the hpvaa gene of $\mathrm{H}$. parallela}

The full-length sequence of hpvaa cDNA was successfully obtained by RACE technology (Table 1). The predicted hpvaa open reading frame is $1845 \mathrm{bp}$, encoding a 614-amino acid protein with a calculated molecular mass of $67.8 \mathrm{kDa}$ and an isoelectric point of 4.90. HpVAA protein, which includes two putative conserved domains, ATP-synt_ab_N and ATP-synt_ab_C, and a Walker A (GAFGCGKT) motif and a Walker B (SMMAD) motif, showed the same structural characteristics as V-ATPase subunit A from other species (Figure 1A). In addition, using MEGA 4.0 and analysis of the neighbor-joining phylogenetic tree, we found that HpVAA is clearly closely related with Tribolium castaneum XP_005179973.1 (Figure 1B). SWISS-MODEL online software was used to construct the three-dimensional model structure of HpVAA (Figure 1C).

Table 1. Nucleotide primers used for RACE and qRT-PCR amplification of hpvaa.

\begin{tabular}{l|l|l}
\hline Primer & Orientation & Primer DNA sequence \\
\hline V1 & Forward & GCTATGTACGAGYTSGTSCG \\
\hline V2 & Reverse & TCAGAGTTGGARTAYTTGGA \\
\hline V3 & Forward & CAGTTCTACCGAAAGGGGTTTCCTGTCCGT \\
\hline V4 & Reverse & CAACGTGTGCTGGACTCTCTGTTCCCATGTG \\
\hline V5 & Forward & gegtegacgtATGTCGAGATTACCGAAA \\
\hline V6 & Reverse & ttgcggcegcATCTTCCAAATTCCTAAA \\
\hline VqPCR/F & Forward & AAGCAGGTGCACATTTAACTGGAGG \\
\hline VqPCR/R & Reverse & CGAGGTTGTCGAACTGGCCATACTT \\
\hline Actin/F & Forward & ATGTTGCCATCCAAGCTGTA \\
\hline Actin/R & Reverse & CCAAACGCAAAATAGCATGA \\
\hline
\end{tabular}

Genetics and Molecular Research 15 (3): gmr.15038994 
A

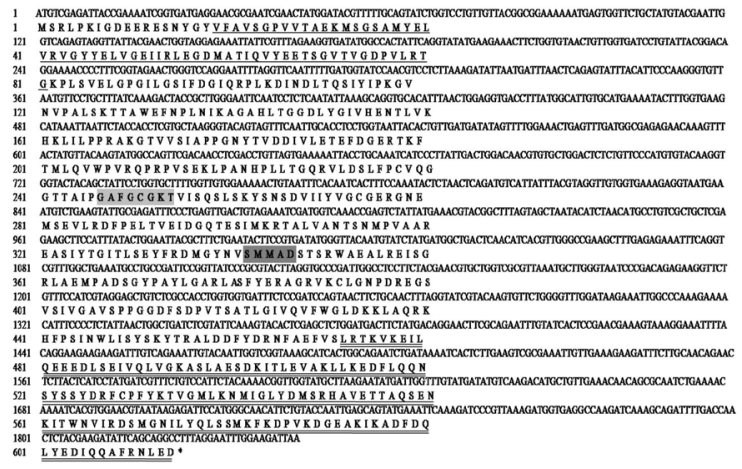

B

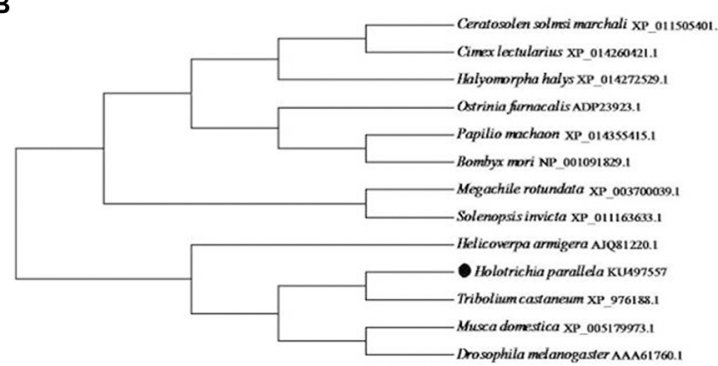

C

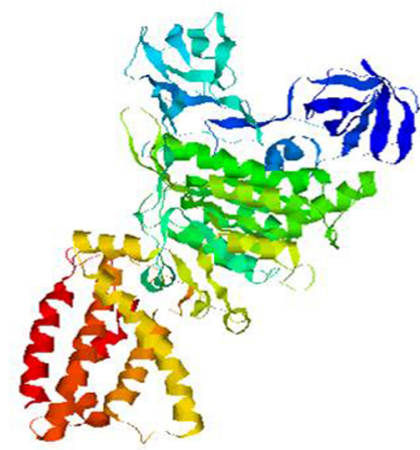

Figure 1. A. Open reading frame and deduced amino acid sequence of the hpvaa gene. Single lines indicate ATPsynt_ab_N, double lines indicate ATP-synt_ab_C, 50\% gray indicates the Walker A (GAFGCGKT) motif, and 25\%

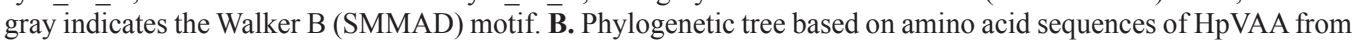
H. parallela and other known insects. C. Three-dimensional-modeled structures of HpVAA.

\section{Expression of pET30a-hpvaa in E. coli}

About $72 \mathrm{kDa}$ band was visible on the gel of SDS-PAGE (Figure 2A), which was consistent with the predicted molecular weight. The recombinant protein existed in the form of an inclusion body. Western blot analysis demonstrated a clear signal with a band appearing at $72 \mathrm{kDa}$ (Figure 2B).

Genetics and Molecular Research 15 (3): gmr.15038994 

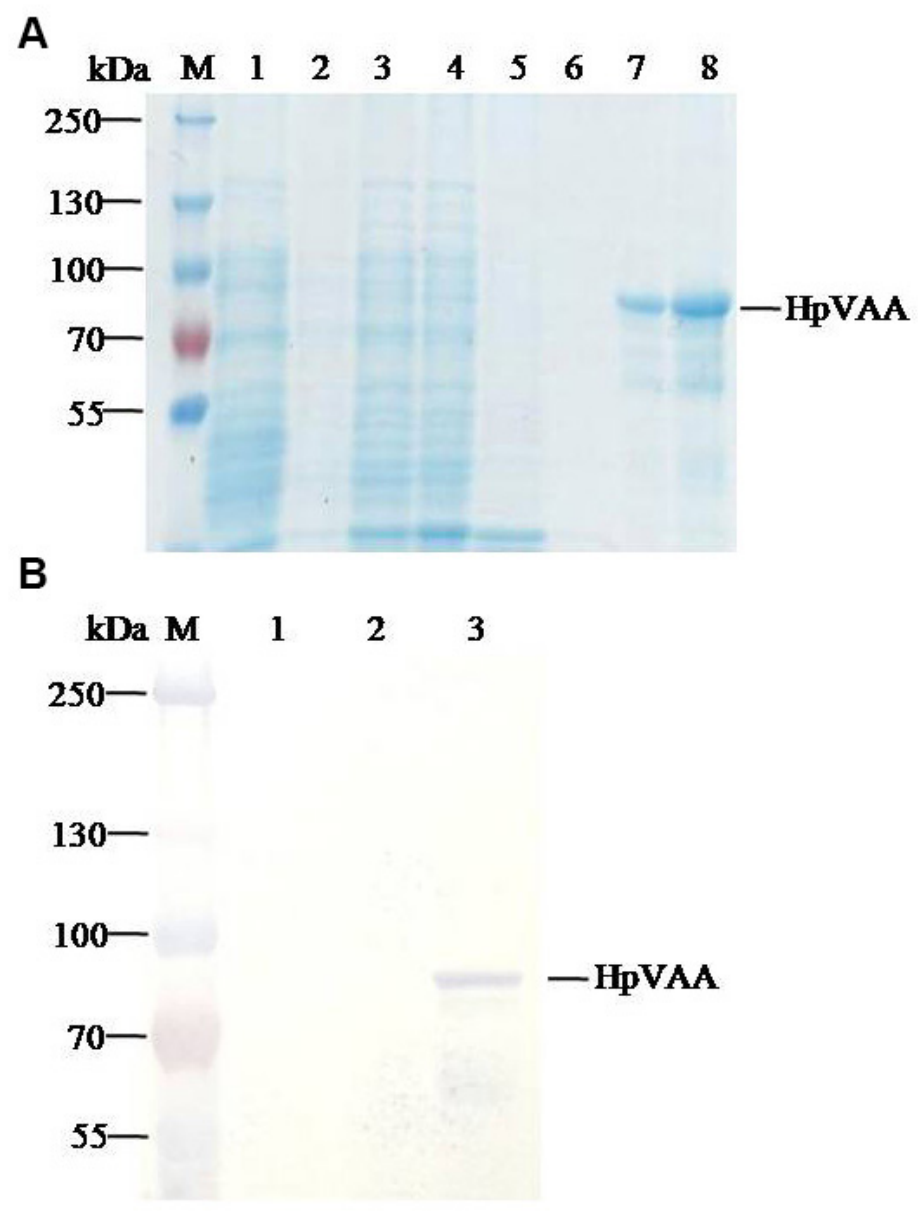

Figure 2. A. Expression of the recombinant HpVAA protein analyzed by SDS-PAGE in E. coli. Lane $M=$ marker protein; lanes 1-4 = supernatant; lanes 5-8= precipitate. Lanes 1 and $5=$ BL21(pET30a); lanes 2 and $6=$ BL21(pET30a-hpvaa), not induced; lanes 3, 4, 7, and $8=$ BL21(pET30a-hpvaa) induced for 4 and $8 \mathrm{~h}$, respectively. B. Western bot analysis of the recombinant expression of HpVAA in E. coli. Lane $M=$ marker protein; lane $1=$ BL21(pET30a); lane 2 = BL21(pET30a-hpvaa), not induced; lane 3 = BL21(pET30a-hpvaa), induced.

\section{Ligand blot of HVAA protein in E. coli BL21}

The Cry8Ea3 ligand blot revealed strong binding to a protein of $72 \mathrm{kDa}$ (Figure 3).

\section{Transcriptional analysis of hpvaa in different larval tissues of $H$. parallela}

qRT-PCR analysis showed variable expression levels of hpvaa in different tissues of $H$. parallela third-instar larvae, with the highest expression observed in the Malpighian tubules and lowest expression in fat body (Figure 4).

Genetics and Molecular Research 15 (3): gmr.15038994 


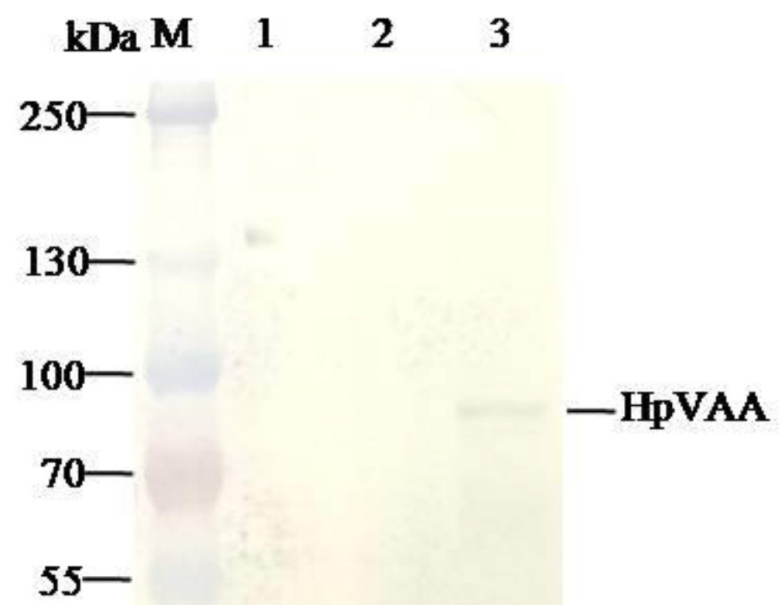

Figure 3. Ligand blot analysis of recombinant expression of HpVAA in E. coli. Lane $M=$ marker protein; lane $1=$ BL21(pET30a); lane 2 = BL21(pET30a-hpvaa), not induced; lane 3 = BL21(pET30a-hpvaa), induced.

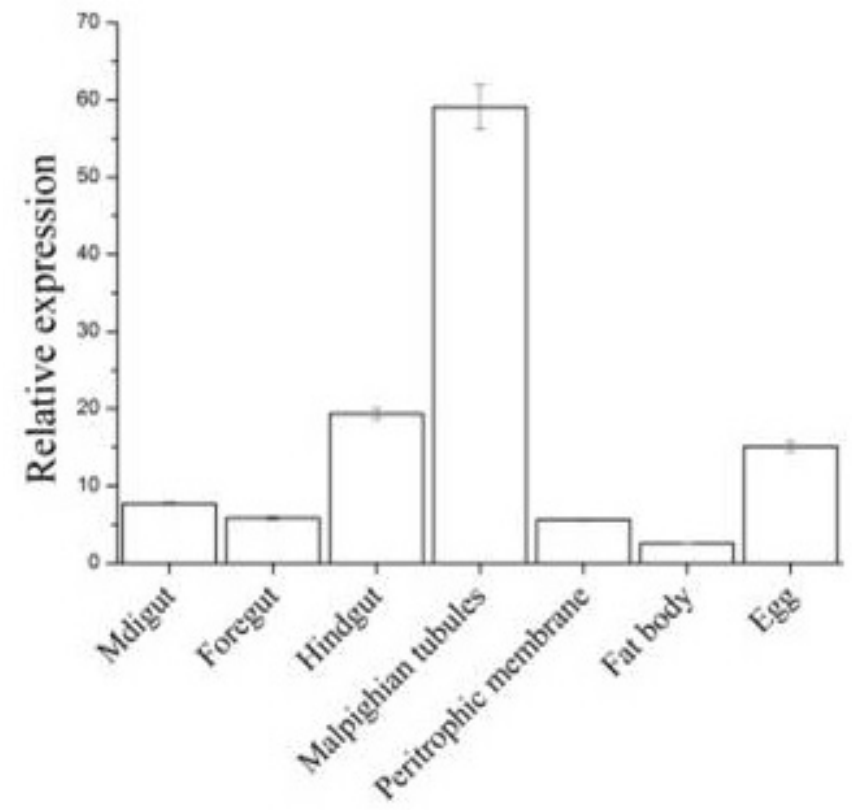

Figure 4. Expression level of the hpvaa in different tissues of the third-instar larvae of H. parallela.

Genetics and Molecular Research 15 (3): gmr.15038994 


\section{DISCUSSION}

The V-ATPases were usually recognized as ATP-driven proton pumps which involved in various cellular processes (Cotter et al., 2015). V-ATPase was demonstrated to play vital role in abundant physiological function such as protein degradation, storage of secretory proteins, and endocytosis of receptors (Forgac, 2007). V-ATPase which was extensively involved in the process of proton transport across cell membranes is appropriately divided into two groups (V1 domain and V0 domain). V1 domain was generally regarded as ATP hydrolysis and is consists of A-H subunits. The other V0 domain (composed of subunits a, d, e, c, and c) was characterized with proton transport. The A Walker site in the A subunit is the binding site of ATP, and this binding to ATP is critical for proper formation of the V1 domain. In this study, we cloned the V-ATPase A subunit from $H$. parallela and found the conserved region of A Walker. V-ATPase regulates its activity in cells by dissociation and assembly of the V 0/V1 domains. Because of its important regulatory function in the cell, in recent years, V-ATPase has been increasingly used as a drug target.

In the insect midgut, V-ATPase in the goblet cell column and transport of $\mathrm{H}^{+} / \mathrm{K}^{+}$provides the primary sources of energy to insects for the secretion and absorption of nutrients. In recent years, research has shown that V-ATPase A and B subunits are the binding proteins of Cry1 Ac protein in Heliothis virescens, Plodia interpunctella (Candas et al., 2003), and Helicoverpa armigera (Chen et al., 2010). The B subunit is non-catalytic, whereas the A subunit is catalytic for ATP hydrolysis. The findings of two-dimensional difference gel electrophoresis validated that the expression of V-ATPase subunit B was enhanced in the midgut of Bt-resistant and -susceptible $P$. interpunctella larva (Candas et al., 2003). In the present study, transcriptional analysis of hpvaa in different tissues of $H$. parallela larval revealed that the highest expression level was in Malpighian tubules while the lowest expression was in fat body. Furthermore, the $H$. parallela V-ATPase A subunit can bind to Cry8Ea3, suggesting that the V-ATPase A subunit contributes to the interaction between Cry8Ea3 and brush border membrane vesicles.

\section{REFERENCES}

Aroonkesorn A, Pootanakit K, Katzenmeier G and Angsuthanasombat C (2015). Two specific membrane-bound aminopeptidase $\mathrm{N}$ isoforms from Aedes aegypti larvae serve as functional receptors for the Bacillus thuringiensis Cry4Ba toxin implicating counterpart specificity. Biochem. Biophys. Res. Commun. 461: 300-306. http://dx.doi. org/10.1016/j.bbrc.2015.04.026

Bravo A, Hendrickx S, Jansens S and Peferoen M (1992). Immunocytochemical analysis of specific binding of Bacillus thuringiensis insecticidal crystal proteins to lepidopteran and coleopteran midgut membranes. J. Invertebr. Pathol. 60: 247-253. http://dx.doi.org/10.1016/0022-2011(92)90005-O

Bayyareddy K, Andacht TM, Abdullah MA and Adang MJ (2009). Proteomic identification of Bacillus thuringiensis subsp. israelensis toxin Cry4Ba binding proteins in midgut membranes from Aedes (Stegomyia) aegypti Linnaeus (Diptera, Culicidae) larvae. Insect Biochem. Mol. Biol. 39: 279-286. http://dx.doi.org/10.1016/j.ibmb.2009.01.002

Candas M, Loseva O, Oppert B, Kosaraju P, et al. (2003). Insect resistance to Bacillus thuringiensis: alterations in the indianmeal moth larval gut proteome. Mol. Cell. Proteomics 2: 19-28. http://dx.doi.org/10.1074/mcp.M200069$\underline{\mathrm{MCP} 200}$

Chen LZ, Liang GM, Zhang J, Wu KM, et al. (2010). Proteomic analysis of novel Cry1 Ac binding proteins in Helicoverpa armigera (Hübner). Arch. Insect Biochem. Physiol. 73: 61-73. http://dx.doi.org/10.1002/arch.20340

Cotter K, Stransky L, McGuire C and Forgac M (2015). Recent Insights into the Structure, Regulation, and Function of the V-ATPases. Trends Biochem. Sci. 40: 611-622. http://dx.doi.org/10.1016/j.tibs.2015.08.005

Forgac M (2007). Vacuolar ATPases: rotary proton pumps in physiology and pathophysiology. Nat. Rev. Mol. Cell Biol. 8: 917-929. http://dx.doi.org/10.1038/nrm2272

Genetics and Molecular Research 15 (3): gmr.15038994 
Griffitts JS, Haslam SM, Yang T, Garczynski SF, et al. (2005). Glycolipids as receptors for Bacillus thuringiensis crystal toxin. Science 307: 922-925. http://dx.doi.org/10.1126/science.1104444

Hua G, Park Y and Adang MJ (2014). Cadherin AdCad1 in Alphitobius diaperinus larvae is a receptor of Cry3Bb toxin from Bacillus thuringiensis. Insect Biochem. Mol. Biol. 45: 11-17. http://dx.doi.org/10.1016/j.ibmb.2013.10.007

Gómez JE, López-Pazos SA and Cerón J (2012). Determination of Cry toxin activity and identification of an aminopeptidase $\mathrm{N}$ receptor-like gene in Asymmathetes vulcanorum (Coleoptera: Curculionidae). J. Invertebr. Pathol. 111: 94-98. http://dx.doi.org/10.1016/j.jip.2012.06.003

Knight PJ, Knowles BH and Ellar DJ (1995). Molecular cloning of an insect aminopeptidase $\mathrm{N}$ that serves as a receptor for Bacillus thuringiensis CryIA(c) toxin. J. Biol. Chem. 270: 17765-17770. http://dx.doi.org/10.1074/jbc.270.30.17765

Krishnamoorthy M, Jurat-Fuentes JL, McNall RJ, Andacht T, et al. (2007). Identification of novel Cry1 Ac binding proteins in midgut membranes from Heliothis virescens using proteomic analyses. Insect Biochem. Mol. Biol. 37: 189-201. http://dx.doi.org/10.1016/j.ibmb.2006.10.004

Li H, Liu R, Shu C, Zhang Q, et al. (2014). Characterization of one novel cry8 gene from Bacillus thuringiensis strain Q527. World J. Microbiol. Biotechnol. 30: 3075-3080. http://dx.doi.org/10.1007/s11274-014-1734-9

McNall RJ and Adang MJ (2003). Identification of novel Bacillus thuringiensis Cry1 Ac binding proteins in Manduca sexta midgut through proteomic analysis. Insect Biochem. Mol. Biol. 33: 999-1010. http://dx.doi.org/10.1016/S0965-1748(03)00114-0

Pardo-López L, Gómez I, Muñoz-Garay C, Jiménez-Juarez N, et al. (2006a). Structural and functional analysis of the pre-pore and membrane-inserted pore of Cry1Ab toxin. J. Invertebr. Pathol. 92: 172-177. http://dx.doi.org/10.1016/j.jip.2006.02.008

Pardo-López L, Soberón M and Bravo A (2013). Bacillus thuringiensis insecticidal three-domain Cry toxins: mode of action, insect resistance and consequences for crop protection. FEMS Microbiol. Rev. 37: 3-22. http://dx.doi. org/10.1111/j.1574-6976.2012.00341.x

Sato R, Takeuchi K, Ogiwara K, Minami M, et al. (1994). Cloning, heterologous expression, and localization of a novel crystal protein gene from Bacillus thuringiensis serovar japonensis strain buibui toxic to scarabaeid insects. Curr. Microbiol. 28: 15-19. http://dx.doi.org/10.1007/BF01575980

Shu C, Yan G, Wang R, Zhang J, et al. (2009a). Characterization of a novel cry8 gene specific to Melolonthidae pests: Holotrichia oblita and Holotrichia parallela. Appl. Microbiol. Biotechnol. 84: 701-707. http://dx.doi.org/10.1007/ $\underline{\text { s00253-009-1971-2 }}$

Shu C, Yu H, Wang R, Fen S, et al. (2009b). Characterization of two novel cry8 genes from Bacillus thuringiensis strain BT185. Curr. Microbiol. 58: 389-392. http://dx.doi.org/10.1007/s00284-008-9338-y

Soberón M, Gill SS and Bravo A (2009). Signaling versus punching hole: How do Bacillus thuringiensis toxins kill insect midgut cells? Cell. Mol. Life Sci. 66: 1337-1349. http://dx.doi.org/10.1007/s00018-008-8330-9

Tanaka S, Miyamoto K, Noda H, Jurat-Fuentes JL, et al. (2013). The ATP-binding cassette transporter subfamily C member 2 in Bombyx mori larvae is a functional receptor for Cry toxins from Bacillus thuringiensis. FEBS J. 280: 1782-1794. http://dx.doi.org/10.1111/febs. 12200

Upadhyay SK and Singh PK (2011). Role of alkaline phosphatase in insecticidal action of Cry1Ac against Helicoverpa armigera larvae. Biotechnol. Lett. 33: 2027-2036. http://dx.doi.org/10.1007/s10529-011-0665-x

Vadlamudi RK, Ji TH and Bulla LAJ, Jr. (1993). A specific binding protein from Manduca sexta for the insecticidal toxin of Bacillus thuringiensis subsp. berliner. J. Biol. Chem. 268: 12334-12340.

Yu H, Zhang J, Huang D, Gao J, et al. (2006). Characterization of Bacillus thuringiensis strain Bt185 toxic to the Asian cockchafer: Holotrichia parallela. Curr. Microbiol. 53: 13-17. http://dx.doi.org/10.1007/s00284-005-0097-8

Yamaguchi T, Sahara K, Bando H and Asano S (2008). Discovery of a novel Bacillus thuringiensis Cry8D protein and the unique toxicity of the Cry8D-class proteins against scarab beetles. J. Invertebr. Pathol. 99: 257-262. http://dx.doi. org/10.1016/j.jip.2008.05.009

Zhang X, Candas M, Griko NB, et al. (2006). Amechanism of cell death involving an adenylyl Cyclase/PKA signaling pathway is induced by the Cry1Ab toxin of Bacillus thuringiensis. Proc. Natl. Acad. Sci. USA 103: 989-9902. http:// dx.doi.org/10.1073/pnas.0604017103

Zhang Y, Zheng G, Tan J, Li C, et al. (2013). Cloning and characterization of a novel cry8Ab1 gene from Bacillus thuringiensis strain B-JJX with specific toxicity to scarabaeid (Coleoptera: Scarabaeidae) larvae. Microbiol. Res. 168: 512-517. http://dx.doi.org/10.1016/j.micres.2013.03.003

Zúñiga-Navarrete F, Gómez I, Peña G, Bravo A, et al. (2013). A Tenebrio molitor GPI-anchored alkaline phosphatase is involved in binding of Bacillus thuringiensis Cry3Aa to brush border membrane vesicles. Peptides 41: 81-86. http:// dx.doi.org/10.1016/j.peptides.2012.05.019

Zúñiga-Navarrete F, Gómez I, Peña G, Amaro I, et al. (2015). Identification of Bacillus thuringiensis Cry3Aa toxin domain II loop 1 as the binding site of Tenebrio molitor cadherin repeat CR12. Insect Biochem. Mol. Biol. 59: 50-57. http://dx.doi.org/10.1016/j.ibmb.2015.02.002

Genetics and Molecular Research 15 (3): gmr.15038994 